\title{
Evidence for an involvement of associative conditioning in reflex modification of the acoustic startle response with gaps in background noise
}

\author{
KEVIN M. CROFTON, KAREN F. DEAN, and LARRY P. SHEETS \\ Neurotoxicology Division, Health Effects Research Laboratory, \\ U.S. Environmental Protection Agency, Research Triangle Park, North Carolina \\ and \\ DAVID B. PEELE \\ NSI Environmental Sciences, Research Triangle Park, North Carolina
}

\begin{abstract}
The experiments reported here were designed to determine the role of associative conditioning in reflex modification of the acoustic startle response, using gaps in background noise. The first experiment was done to characterize the effects of repeated testing for 9 days with 20-msec gaps in white noise as the preliminary stimulus (S1) and a $120-\mathrm{dB}, 40-\mathrm{msec} 13-\mathrm{kHz}$ tone as the eliciting stimulus (S2). The second experiment was a test of associative conditioning. Three groups of rats were tested daily for 6 days under one of the following conditions: S1 and S2 paired in a contingent manner, S2 only, or S1 only. All groups then received the contingent pairing of S1 and S2 for an additional 9 days of testing. In the third experiment, a separate group of rats was tested with either contingent or noncontingent presentation of the S1 and S2 for 6 days, and then, on the 7th day, both groups received the stimuli in a contingent fashion. Results indicate that the amount of inhibition increases with repeated, daily testing, and that it achieves asymptotic levels of inhibition after 5-6 daily sessions. The presentation of S1 and S2 together is a necessary, but not sufficient, condition for normal development of inhibition. Alternatively, the contingency that exists between the two stimuli is likely to be the determining factor necessary for development of the inhibition. These data imply that an associative learning process may be a major factor in the gap-inhibition phenomenon.
\end{abstract}

Reflex modification of the acoustic startle response (ASR) is the change in a stimulus-elicited response due to a perceptible antecedent change in the sensory environment (for a review, see Hoffman \& Ison, 1980). A wide variety of sensory stimuli have been demonstrated to inhibit the ASR in the rat, including white noise and tone bursts (Buckland, Buckland, Jamieson, \& Ison, 1969; Hoffman \& Searle, 1965, 1968; Ison \& Hammond, 1971); light flashes (Ison \& Hammond, 1971; Schwartz, Hoffman, Stitt, \& Marsh, 1976); noise onsets, offsets, and frequency shifts (Cranney \& Cohen, 1985; Hoffman \&

Portions of these data were presented at the 1988 annual meeting of the Society for Neuroscience, Toronto, Ontario. This manuscript has been reviewed by the Health Effects Research Laboratory, U.S. Environmental Protection Agency, and approved for publication. Mention of trade names or commercial products does not constitute endorsement or recommendation for use. The authors would like to thank R. Hamrick and T. Knight for their technical assistance. They would also like to thank M. Stanton, M. Davis, J. A. Foss, and J. R. Ison for their comments on the manuscript. Address correspondence to Kevin $M$. Crofton, Neurotoxicology Division (MD-74B), U.S. Environmental Protection Agency, Research Triangle Park, NC 27711.
Searle, 1965; Hoffman \& Wible, 1969; Stitt, Hoffman, \& Marsh, 1973; Stitt, Hoffman, Marsh, \& Boskoff, 1974); cutaneous stimuli (Pinckney, 1976; Russo, Reiter, \& Ison, 1975); and gaps in background noise (Ison, 1982). Although the anatomical basis for reflex modification is not clear (see Wu, Suzuki, \& Siegel, 1988), previous work has suggested a feed-forward inhibition (see Hoffman \& Ison, 1980). Earlier data showed that inhibition may occur on the first trial without conditioning, but experiential factors have not been ruled out (Ison, Hammond, \& Krauter, 1973; Ison \& Leonard, 1971).

Brief silent periods in background noise (gaps) inhibit the ASR, with the amount of inhibition directly related to the duration of the gap (Ison, 1982). This procedure has been suggested as a means of measuring auditory temporal acuity (Ison, 1982). With the use of this procedure, the threshold for temporal resolution has been estimated at $3.5 \mathrm{msec}$ in the rat (Ison, 1982), a value similar to the estimates of temporal acuity in humans derived with a variety of techniques (Fitzgibbons \& Wightman, 1982; Green, 1971; Ison \& Pinckney, 1983; Plomp, 1964). This procedure also has been suggested as a method for determining the effects of drugs or toxicants on auditory tem- 
poral acuity (Kellogg, Ison, \& Miller, 1983; Wecker \& Ison, 1984).

Recent work done to examine the ontogeny of temporal acuity in the rat has shown that, with this technique, a training requirement of two or more test sessions is required for animals to reach asymptotic acuity (Dean, Sheets, Crofton, \& Reiter, 1990). Previous work done with either visual prestimuli (Wecker, 1985) or cutaneous prestimuli (Wu, Ison, Wecker, \& Lapham, 1985) has led to similar results. These studies suggest a possible learning component in this reflex modification procedure, a component previously ruled out in the case of inhibition by tone bursts (Ison et al., 1973; Ison \& Leonard, 1971).

Our purpose in the present study was to ascertain whethe $e_{1}$ or not associative learning processes are involved in gap inhibition of the ASR. First, it was necessary to characterize the inhibition of the ASR by using gaps in background noise across repeated, daily testing. Preliminary data indicated that four to six sessions are required to achieve an asymptotic level of inhibition (Crofton, Sheets, Dean, \& Peele, 1988). This was accomplished in Experiment 1 by testing animals daily for 9 days. If associative processes play a role in determining the amount of inhibition, then one would expect to see an increase in the amount of inhibition over days. Second, it was necessary to determine whether gap inhibition of the ASR is related to a learned association between the gap and eliciting stimulus or to other nonassociative features of repeated testing. This was accomplished in the last two experiments. In Experiment 2, independent groups of rats were tested repeatedly with either the gap or the eliciting stimulus, and then they were tested on the standard gapinhibition paradigm. The purpose of these manipulations was to assess the influence of repeated exposure to either of the two stimuli alone on inhibition of startle by gaps in noise. In Experiment 3, the contingent relationship between $\mathrm{S} 1$ and $\mathrm{S} 2$ was altered by using the truly random control procedure of Rescorla (1967). During daily sessions, rats were exposed to both S1 and S2 in an explicitly unpaired fashion. If the results observed in Experiment 1 were due to associative mechanisms, then presentation of stimuli in a noncontingent manner for six sessions should have resulted in less inhibition when the stimuli were subsequently paired.

\section{METHOD}

\section{Animals}

Adult male, Long-Evans hooded rats, approximately 70 days of age (Charles River, Inc.), were housed in a facility that was maintained on a 12:12-h light:dark photoperiod $(0600: 1800 \mathrm{~h})$, with controlled temperature $\left(22^{\circ} \pm 2.0^{\circ} \mathrm{C}\right)$ and relative humidity $(40 \% \pm 20 \%)$. Food (Purina Lab Chow) and water were available ad lib.

\section{Apparatus}

Testing was conducted in eight sound-attenuated chambers, each containing a wire mesh, plastic-framed test cage, mounted on a loadcell/force-transducer assembly designed to measure vertical force (see Ruppert, Dean, \& Reiter, 1984, for details). Two speakers were suspended from the ceiling of each chamber. One speaker (Motorola $5.0 \times 12.5 \mathrm{~cm}$ piezoelectric tweeter) presented the eliciting stimulus (S2) (13-kHz, 120-dB[A], 40-msec tone with a 2.5msec rise/decay). A second speaker (Creative Acoustics, $16 \Omega$ ) delivered background noise at $80 \mathrm{~dB}(A)$. The spectrum of this noise, measured with a Spectrascope Model SSD330 real-time analyzer, had approximately equal power from $200 \mathrm{~Hz}$ to $15 \mathrm{kHz}( \pm 15 \mathrm{~dB}$, with the peak between 3-8 kHz); output then dropped from 15 to $20 \mathrm{kHz}(-40 \mathrm{~dB})$. All sound measurements (SPL) were made with a Brüel \& Kjaer Type 2209 sound level meter and a 0.5 -in. Type 4165 microphone.

\section{Procedure}

Each rat was placed in an individual test cage, and testing began following a 10-min adaptation period at a low background noise level $(35 \mathrm{~dB})$. The background noise was increased to $80 \mathrm{~dB}$ during testing. The animals were tested in one of four testing conditions. In the first study, rats $(n=8)$ were tested daily for 9 days, using 25 blank-control trials (S2 alone) and 25 gap trials (S1-S2 pairs). Trials were presented in a computer-generated, semirandom but balanced fashion (i.e., each condition, gap or blank control, was presented in a random order within each of 25 pairs of trials). For S1-S2 trials, the background noise $(80 \mathrm{~dB})$ continued until $190 \mathrm{msec}$ prior to the presentation of the eliciting stimulus (S2). At this time, background noise was attenuated to $35 \mathrm{~dB}$ for $20 \mathrm{msec}$, and then resumed at $80 \mathrm{~dB}$ for $170 \mathrm{msec}$ prior to and during the eliciting stimulus, thereby producing a 20 -msec gap (S1) in the background noise. The decay/onset time for the gap signal was $<1$ msec. For \$2-alone trials, there was no attenuation of the background noise.

In addition to the previously described test conditions, the second study included a third test condition-gap only ( $\mathrm{S} 1$ alone). Rats ( $n=14-16$ per group) were assigned to one of the three test conditions ( $S 1$ alone, S2 alone, or S1-S2) and tested for 6 days. For the S1-alone group, there was no presentation of the eliciting stimulus. For the $S 2$-alone group, there was no presentation of the gap stimulus. The $\mathrm{S1-S2}$ group received stimuli presented as described above for the first experiment. After 6 days of testing with these 3 conditions, all groups were tested on S1-S2 pairs for an additional 10 days (Days 7-16).

In the third experiment, two groups of rats ( $n=15-16$ per group) were used to examine the relationship between the S1-S2 pairings. The first group received S1-S2 pairs as described above (contingent), whereas the second group received S1-S2 pairs presented in a noncontingent manner on half the trials, the other half being blank control trials (see Rescorla, 1967). While the intertrial interval (ITI) remained fixed at $15 \mathrm{sec}$, the interstimulus interval (ISI) was random within that $15 \mathrm{sec}$ (i.e., the gap was presented randomly during the trial). Each group was tested under the assigned condition for 6 days. On Day 7, both groups were tested on the contingent $\mathrm{S} 1-\mathrm{S} 2$ pairings.

Data were collected for $64 \mathrm{msec}$ following the onset of S2. The next trial began immediately after the data-collection period. The analog signal for each response was digitized at $1 \mathrm{kHz}$ and was converted to grams, using a previously determined calibration curve for each load cell. The peak response amplitude was taken from each animal's average response curve and was calculated across trials at a given condition for each day. Percentage data were calculated from individual response curve data, as the response amplitude of the $\mathrm{S} 2$-alone trials expressed relative to the response amplitude of the paired S1-S2 trials. The mean of each animal's responses was used to calculate a group mean. The ITI (time between presentations of $\mathbf{S 2}$ ) was fixed at $15 \mathrm{sec}$, and the ISI (time from onset of S1 to onset of S2) was fixed at $190 \mathrm{msec}$, except where noted.

All data were analyzed using multivariate ANOVA procedures for repeated measures. The analyses were conducted with condition group as the between-animal factor, and session (days) and gap 
(gap trial vs. control trials) as within-animal factors. HotellingLawley Trace corrected $F$ approximations were used when appropriate. Significant interactions were followed by step-down tests to analyze for main effects.

\section{RESULTS}

The results of Experiment 1 are shown in Figure 1. Inhibition of the ASR to gaps in background noise was apparent on the first day of testing (30\%); however, the amount of inhibition increased (to $80 \%$ ) with repeated testing. Asymptotic inhibition occurred after approximately 5 days of testing. For the amplitude data, there was a significant interaction between control and gap trials across days $[F(8,56)=6.30, p<.01]$. There were significant differences in amplitudes on all days $(p<.05)$. The inhibition on Day 1 of approximately $30 \%$ was replicated in all three experiments (Figures 1,3, and 4). For the percentage data, there was a significant effect of day $[F(8,56)=23.61, p<.0001]$, and contrast analysis of the data indicates that Days 3-9 were significantly different from Day 1 [all $F \mathrm{~s}(1,7)>10.8, p<.05$ ].

Percentage data from the first trial on each day are presented in Figure 2. These data indicate an increasing inhibition across days, similar to that seen in Figure 1. The inset in Figure 2 illustrates the percentage data from all trials on Day 1. The data indicate a lack of inhibition on the first two trials on the 1st day, followed by no more than $50 \%$ inhibition on any of the remaining trials on the 1 st day. These data are presented for exploratory analysis only, because the experiment was not designed a priori to look at the within-session data.

The results of Experiment 2 are presented in Figure 3. Presentation of either $\mathrm{S1}$ or $\mathrm{S} 2$ alone for 6 days did not produce the same amount of inhibition on Day 7 , when $\mathbf{S} 1$ and $\mathbf{S 2}$ were paired, as was present in the group that received both stimuli in a paired fashion for the first 6 days. The S1-alone group had approximately the same amount of inhibition ( $27 \%$ ) on Day 7 as the S1-S2 group had on Day 1 (Figure 3B). The amount of absolute inhibition also was similar: $58.8 \mathrm{vs.} 69.1 \mathrm{~g}$ in the S1S2 and S1-alone groups, respectively (Figure 3A). On Day 7 , the $\$ 2$-alone group had significantly more inhibjtion ( $\sim 45 \%$ ) than did the $S 1$ group, but significantly less than the S1-S2 group had ( $\sim 75 \%)$. As can be seen in Figure $3 B$, the $\mathbf{S} 2$-alone group also displayed more inhibition on Day $7(\sim 45 \%)$ than did the S1-S2 group on Day $1(\sim 28 \%)$. Again, the absolute inhibition was also

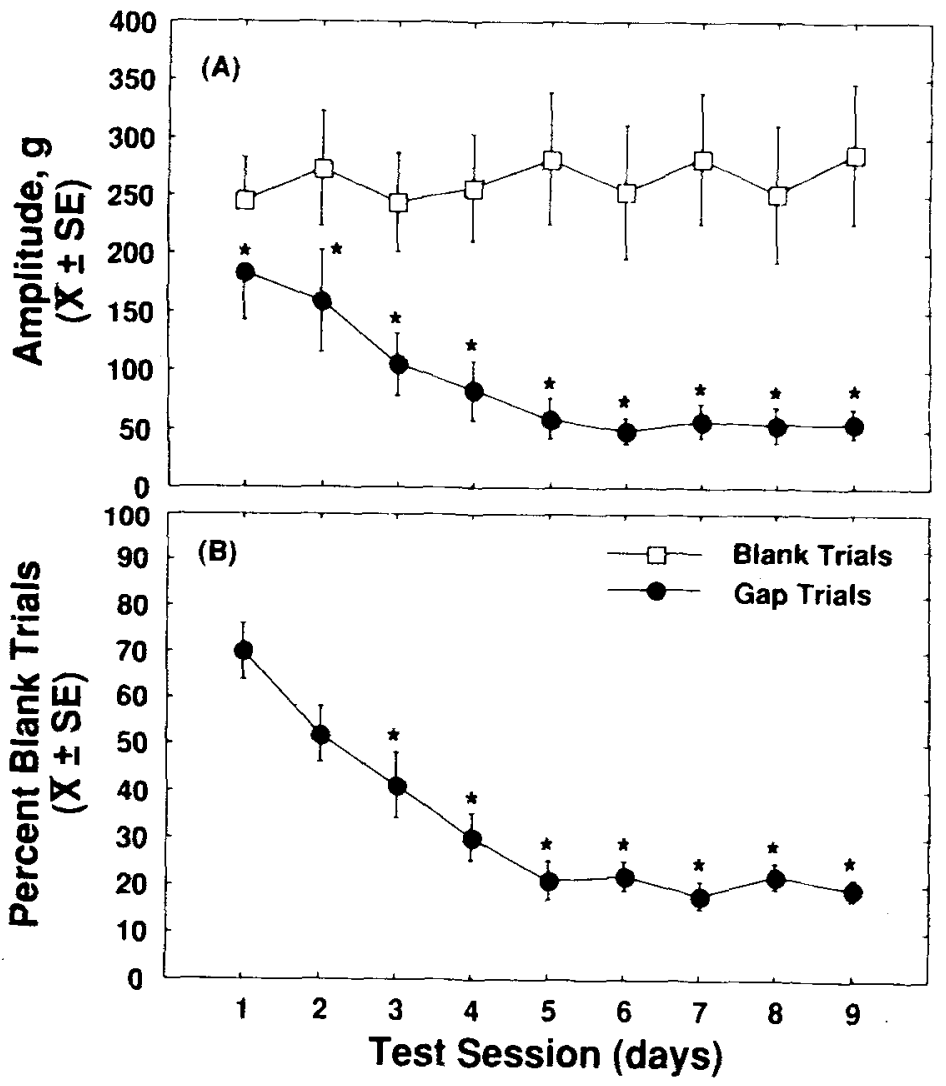

Figure 1. The effect of repeated testing on gap inhibition of the acoustic starthe response. (A) Open symbols represent response amplitudes for S2-alone (blankcontrol) trials; filled symbols represent response amplitudes for S1-S2 trials (*significantly different from S2-alone control). (B) Data represent the response amplitude on S1-S2 trials as a percentage of the S1-alone trials (*significantly different from Session 1). 


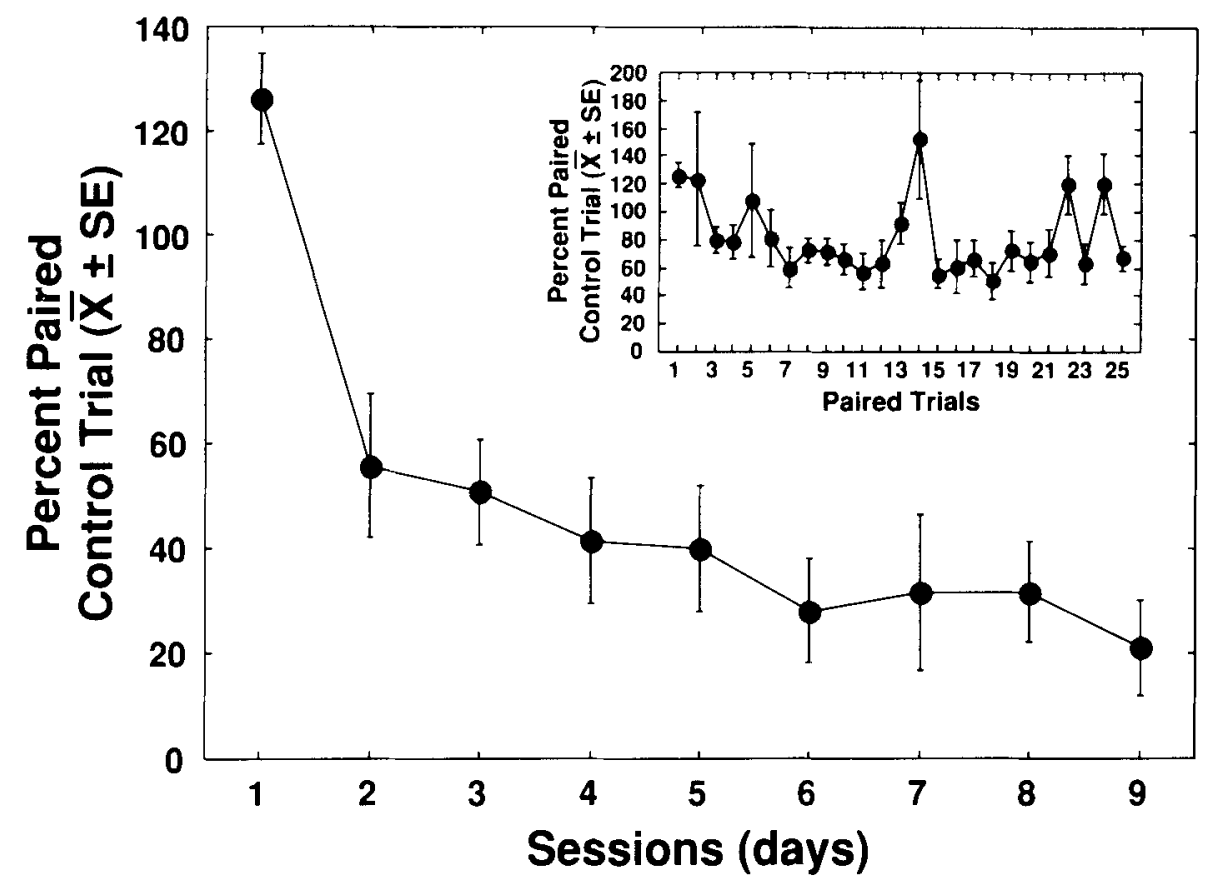

Figure 2. Data from Figure 1 for the first paired trial in each session. Data are presented as group means of the response amplitudes on the S1-S2 trials as a percentage of the paired S2-alone trial. Inset: data for all trials in Session 1.

greater in the S1-alone group than in the S1-S2 group ( 122.3 and $59.0 \mathrm{~g}$, respectively; see Figure $3 \mathrm{~A}$ ). The S1and $\mathrm{S} 2$-alone groups did reach asymptotic performance following repeated testing with paired stimuli after another 5 or 6 days of testing (i.e., there were no differences between any groups on Day 14).

Analysis of the amplitude data revealed a significant gap $\times$ day $\times$ condition interaction (gap $=0$ or $20 \mathrm{msec}$; condition = S1-S2, S1 alone, or S2 alone; day = days of testing) for Days $7-16[F(16,70)=1.90, p<.05]$. Data for the first 6 days were not analyzed because there was no response in the $\mathrm{S1}$-alone group and no inhibition in the S2-alone group during these days. Step-down analyses by day revealed a significant gap $\times$ condition interaction on Days $7,8,9$, and $11[F(2,42)>4.6, p<.01]$. There was a significant effect of gap $\times$ day $\times$ condition (e.g., testing for a difference between means at 0 vs. $20 \mathrm{msec}$ ) on Days 7-9 and 11 in the S1-S2 and S2-alone groups. Analyses for an effect of condition at each day and gap (e.g., testing for differences between means in the three test conditions) revealed no significant effect of condition on any day at $0 \mathrm{msec}$. However, there was a significant effect of condition on all 4 days $[F(2,42)>6.02, p<.005]$. Post hoc comparison of means indicated that this effect was due to a greater inhibition in the S1-S2 group than in either the S1- or the S2alone group on Days $7-9$ and $11(p<.05)$. On Day 10 , there was a significant effect of condition $[F(2,42)=3.93$, $p<.05]$ that was due to an overall lower amplitude in the S1-S2 group than in the S1-alone group $(p<.05)$. There was a significant effect of gap on Days 10 and
$12-16[F(1,42)>103.5, p<.0001]$ that was due to significant inhibition in the $20-\mathrm{msec}$ condition relative to the 0 -msec condition (blank-control trials).

Analysis of the percentage data reflects a similar pattern of effects. There was an overall day $x$ condition interaction $[F(16,70)=3.40, p<.0002]$. Analyses by day revealed significant effects of condition on Days 7-13 and 15. Mean contrast comparisons indicated significantly greater inhibition in the S1-S2 group than in the S1- and S2-alone groups on Days 7-9, 11, and $13(p<.05)$. The S1-alone groups also were significantly different from the S1-S2 group on Days 10,12 , and $15(p<.05)$. The S2alone group was significantly different from the $\mathrm{S} 1$-alone group on Days 7-9 $(p<.05)$.

The data from Experiment 3 are presented in Figure 4. Just as is shown in Figures 1 and 3, presentation of the stimuli ( $\mathbf{S} 1$ and $\mathbf{S 2}$ ) in a paired contingent manner led to asymptotic levels of inhibition after 5 or 6 days at about $35 \%$ of control. The noncontingent group failed to show any inhibition (Days 1-6) until the stimuli were presented in a contingent manner on Day 7 . The amount of inhibition in the noncontingent group on Day 7 (29\%) was similar to that seen in the contingent group on Day $1(26 \%)$. There was no effect of the presentation condition (i.e., contingent vs. noncontingent) on the amplitude of blankcontrol trials.

Analysis of the amplitude data revealed a significant gap $\times$ day $\times$ condition interaction $[F(6,24)=3.05$, $p<.05]$. Step-down analyses by day indicated significant gap $\times$ condition interactions on Days 1-7 $[F(1,29)$ $>6.22, p<.01]$. Analyses by day and gap for an ef- 


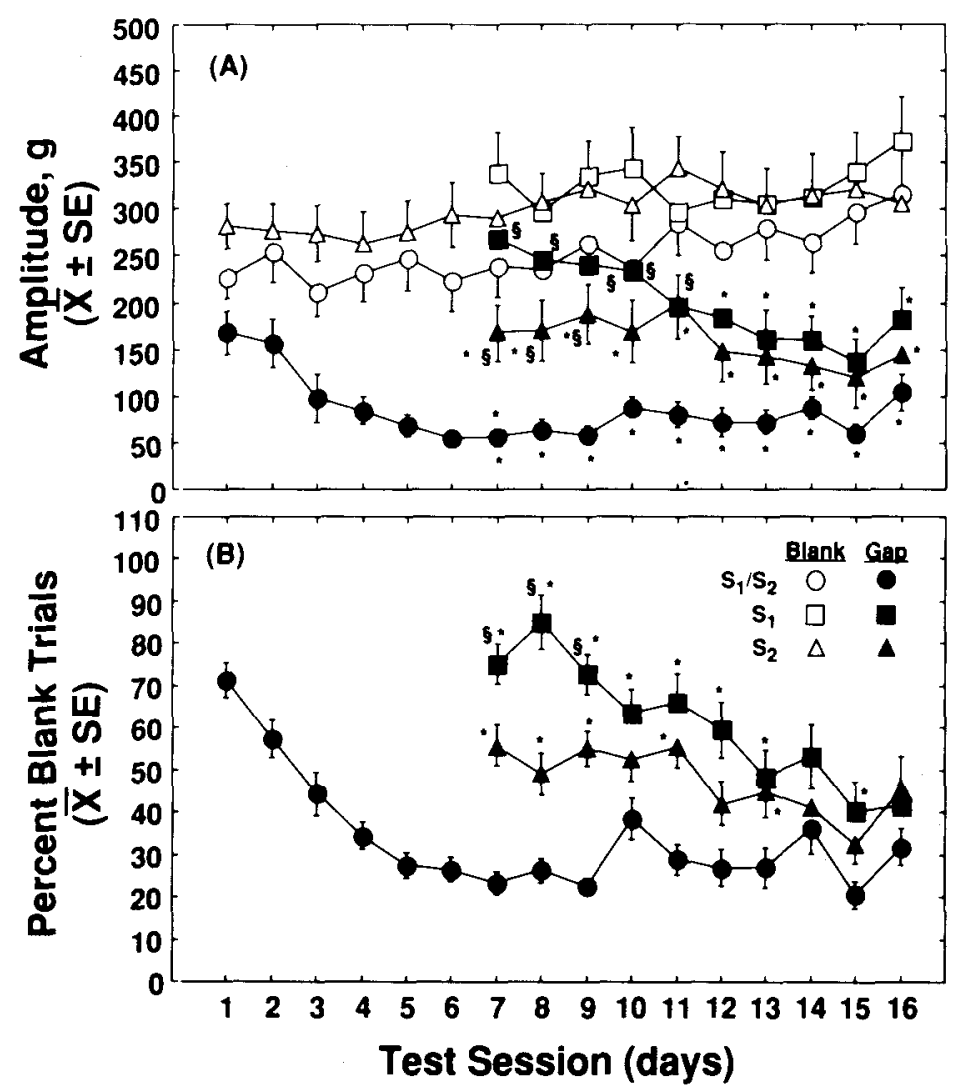

Figure 3. Associative conditioning in gap inhibition of the acoustic startle response. Mean ( $\pm S E$ ) of 14-16 animals/group. (A) Open symbols represent response amplitudes on $\mathrm{S2}$-alone (blank-control) trials; filled symbols represent response amplitudes on S1-S2 trials. Group 1 (circles) received both S1 and S2; Group 2 (squares) received only S1; Group 3 (triangles) received only S2. All groups received both $S 1$ and $S 2$ on Days 7-16. All other conditions were similar to those in Figure 1 (*significantly different from respective blank-control group, \& significantly different from S1-S2 gap group). (B) Data represent the response amplitude on $\mathrm{S1-S2}$ trials as a percentage of the S1-alone trials (*significantly different from S1-S2 gap group, \& significantly different from the S2 gap group).

fect of condition were never significant $[F(1,29)<2.98$, $p>.1]$ for any comparison of the 0 -msec gaps (i.e., $0 \mathrm{msec}$ in the contingent condition vs. $0 \mathrm{msec}$ in the noncontingent condition). However, there was a significant effect of condition for the 20-msec data for Days 1-7 $[F(1,29)>5.98, p<.05]$, indicating a greater inhibition in the 20-msec contingent group than in the $20-\mathrm{msec}$ noncontingent group on all days. Analyses by day and condition for an effect of gap was significant for the contingent group on Days 1-7 $[F(1,28)>5.53, p<.05]$, but the noncontingent group was not significant [all $F \mathrm{~s}(1,28)<0.06, p>.5$, except on Day $7, F(1,28)=$ $3.17, p<.08]$.

Analysis of the percentage data for Figure 4 revealed a day $\times$ condition interaction $[F(6,25)=3.35, p<.01]$. Univariate ANOVAs by day demonstrated significant differences between the contingent and noncontingent conditions on Days 1-7 [all $F \mathrm{~s}(1,30)>15.37, p<.0005$ ].

\section{DISCUSSION}

The results of the present study are consistent with the proposal that inhibition of the ASR by a 20 -msec noisegap stimulus requires four to six daily sessions to reach an asymptotic level. The reliability of data supporting this conclusion includes the fact that a similar time course of inhibition over days was demonstrated in all three experiments (see Figures 1, 3, and 4). This phenomenon is consistent with previous work that demonstrated increasing inhibition of the ASR over three test sessions (Dean et al., 1990). Repeated testing for 4-5 days also is necessary for asymptotic inhibition when visual prestimuli (Wecker, 1985) and cutaneous prestimuli (Wu et al., 1985) are used.

These data appear to contrast with previous reports suggesting that experiential processes were not necessary for reflex modification of the ASR. Krauter, Leonard, and Ison (1973) and Ison et al. (1973) reported that auditory 

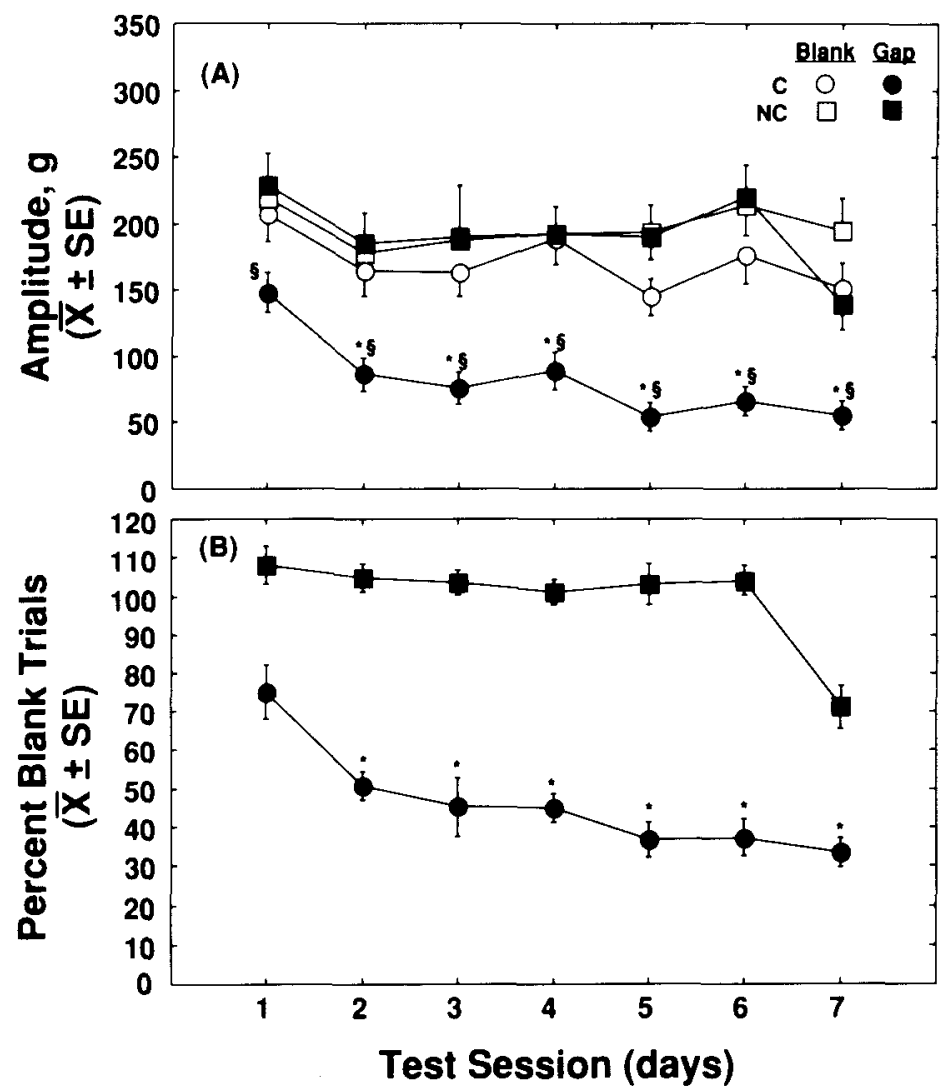

Figure 4. Associativeconditioning of $S 1$ and $S 2$ in gap inhibition of the acoustic startle response. (A) Open symbols represent response amplitudes for S2alone (blank-control) trials; filled symbols represent response amplitudes for S1-S2 trials. The control groups (circles) received $S 1$ and $S 2$ in a contingent (C) manner. The experimental group (squares) received $S 1$ and $S 2$ in a noncontingent (NC) manner for Days 1-6. Both groups then received contingent stimuli on Day 7. All other conditions were similar to those in Figure 1 (*significantly different from blank control, 8 significantly different from noncontingent gap group). (B) Data represent the response amplitude on S1-S2 trials as a percentage of the S1-alone trials (*significantly different from noncontingent gap group).

prestimuli inhibited the ASR on the first presentation. Similar results on the first trial exist for auditory prepulse inhibition of the nictitating membrane reflex (Ison \& Leonard, 1971). However, data from the first experiment (Figure 2, inset) indicate no inhibition on the first two trials.

One possible explanation for these differences may be the stimulus modality employed as the $S 1$. The previous reports were all based on the use of tonal auditory stimuli, whereas in the present study, gaps in background noise were employed. Ison et al. (1973) explored the effects of experience on both auditory and visual prestimuli inhibition of the ASR. These authors showed that auditory inhibition of the ASR increases across trials within the first session, that repeated sessions do not result in increased inhibition, and that intense auditory prestimuli inhibited the ASR on the first trial, whereas weak prestimuli required at least two trials to produce inhibition. Although these results suggest a minor role for experience in the appearance of inhibition, they are in no way predictive of the gradual acquisition of inhibition observed over days in the present data set. The data presented here clearly demonstrate that for gap prestimuli there is increasing inhibition over four to six daily test sessions (Figure 1). Data from the first trial on each day, and data from all trials on Day 1 (Figure 2) suggest a somewhat gradual development for gap inhibition compared to the results of previous reports based on the use of tone-burst prestimuli (Krauter et al., 1973). Ison (personal communication, 1989) has suggested that perhaps gaps represent "weak" prestimuli whose inhibitory influence develops slowly, as opposed to "strong" prestimuli such as tone bursts. These differences are probably not dependent on differences in gap duration or the number of trials per test session, because increasing inhibition has been demonstrated over three daily test sessions involving gaps from 2-64 msec and 240 trials per day (Dean et al., 1990). Given the present findings, it can be said that asymptotic 
inhibition was probably not achieved in that study (Dean et al., 1990), because only three daily test sessions were conducted.

Gap inhibition of the ASR may be influenced or modified by an associative process. This is supported by the facilitory effect of contingent pairing of stimuli in the development of the inhibition (Figure 3 ). When either S1 or $S 2$ was presented alone for the first 6 days and then presented in a predictive pairing on Day 7 , inhibition was much less than that produced when both stimuli were paired in a similar fashion for 7 days. Further testing with paired stimuli leads to asymptotic inhibition in five to six additional test sessions. It is interesting to note that animals presented with $S 2$ (eliciting stimulus) alone for Days 1-6 showed greater inhibition on Day 7, when the stimuli were paired, than did animals that were presented with $S 1$ (the preliminary stimulus, or prestimulus) alone for Days 1-6, and tested on Day 7. The effects of exposure to $\$ 2$ alone for the first 6 days are in agreement with a previous report by Ison et al. (1973), which demonstrated increased inhibition following preexposure to the eliciting stimulus. It is possible that conditioning to contextual cues contributes to this effect. The lack of effect of previous experience of the prestimulus alone (S1) is in agreement with data from Wecker (1985), who demonstrated a similar lack of effect using preexposure to visual prestimuli.

The results of the final experiment, in which contingent and noncontingent paired stimuli were used, provide further evidence that gap inhibition of the ASR involves associative processes. As demonstrated by the use of the truly random control procedure of Rescorla (1967), animals exposed to noncontingent pairing of S1 and S2 failed to develop inhibition of the ASR (Figure 4). Furthermore, once the stimuli were presented in a contingent manner (i.e., on Day 7), inhibition was apparent $(\sim 26 \%)$ and approximated the inhibition found in the contingent group on Day $1(\sim 29 \%)$.

In contrast to the data in previous reports (Hoffman \& Wible, 1970; Ison et al., 1973; Ison \& Leonard, 1971), the data presented here indicate the presence of an associative learning process in reflex modification of the ASR. The reason for the differences between these data and those in previous reports remains to be determined. Gap inhibition may be a distinctly different process from inhibition with pure tone or noise-burst auditory prestimuli. A study of the involvement of associative processes with visual prestimuli failed to demonstrate dependence on contingent pairing of stimuli for maximal inhibition (Wecker, 1985). The involvement of associative processes in reflex modification of the ASR by gaps in background noise and differences with previous reports indicates the need for further studies to determine the optimal conditions for acquisition of inhibition, the role of different sensory stimuli in the process, the role of prestimulus intensity, and the underlying associative processes involved.

The present findings demonstrate the involvement of associative processes in gap inhibition in a manner that excludes other explanations of the observed effects. For instance, it could be argued that the gap stimulus (S1) may initially lack the necessary salience to produce asymptotic levels of inhibition. Mere exposure to $\mathrm{Sl}$ in the course of ASR testing may be responsible for the gradual development of inhibition. However, this fails to explain why repeated testing with $S 1$ alone in the second experiment was not sufficient to produce control asymptotic levels of inhibition when S1 and S2 were paired on Day 7.

Another possible explanation for the observed data involves the nonassociative learning process sensitization (Razran, 1971). Accordingly, exposure to a stimulus like $\mathrm{S} 1$ in the context of the presentation of another highly salient stimulus, S2, may be sufficient to cause an enhanced effect of the gap stimulus. However, this explanation fails to distinguish between the gradual development of inhibition in the standard procedure (Experiment 1) and a lack of an effect of mere exposure to $\mathrm{S} 2$ (Experiment 2) or to the noncontingent presentation of $S 1$ and $S 2$ within a single test session (Experiment 3). A similar line of reasoning could be used to discount the involvement of pseudoconditioning, or the generalization of the startle response to other stimuli in the absence of any association between the two stimuli (Wickens \& Wickens, 1942). If this were the case, then both contingent and noncontingent groups in Experiment 3 should have demonstrated equivalent startle inhibition on Day 7. On the basis of these observations, it is unlikely that the gradual development of asymptotic inhibition of the ASR by gaps in background noise results from sensitization or other nonassociative mechanisms.

Although the form of the conditioned response is not known at the present time, at least two possibilities are plausible. The first is that a rather diffuse preparatory response develops in response to presentation of the gap stimulus as a result of the predictive, contingent relationship between $\mathrm{S} 1$ and S2. Similar suggestions of conditioned preparatory response acquisition have been made for both aversive and appetitive forms of conditioning (Konorski, 1967). Another possibility is that the learned response may serve the purpose of lessening the aversive impact of the eliciting stimulus (Prokasy, 1965). Confirmation of these suggestions awaits further experiments specifically designed to determine the nature of the conditioned response in the gap-inhibition paradigm.

The results of this study have implications for both basic and applied research. The presence of an associative learning process indicates that the gap-inhibition procedure may be used to study cognitive processes. Coupled with current knowledge of the anatomy and pharmacology of the basic startle reflex (see Davis, 1980; Davis, Gendelman, Tischler, \& Gendelman, 1982), and with evidence of cortical modulation of the fear-potentiated startle reflex (Davis, 1988), this procedure may prove useful in the investigation of the neural basis of cognitive processes. There are also implications for applied research. Previous authors have suggested the potential use of the gapinhibition paradigm in the study of auditory temporal acuity (Ison, 1982), specifically, for detecting toxicantor drug-induced alterations in auditory temporal function (Kellogg et al., 1983; Ison, 1984; Wecker \& Ison, 1984). 
Future use of this procedure must take into account an initial training period when determining the effects of chemicals on auditory acuity of the ASR. Also, if a chemical treatment alters gap inhibition, care must be taken to separate learning deficits from sensory deficits. Otherwise, the interpretation of a chemically induced alteration in temporal acuity may be confounded by an induced alteration in a cognitive process.

In summary, this report presents evidence for the involvement of an associative process in the inhibition of the ASR by gaps in background noise. Asymptotic inhibition was shown to require four to six daily sessions with stimuli paired in a contingent fashion. Further work is necessary to define more clearly the cognitive process(es) involved in this phenomenon.

\section{REFERENCES}

Buckland, G., Buckland, J., Jamieson, C., \& Ison, J. R. (1969). Inhibition of the startle response to acoustic stimulation produced by visual prestimulation. Journal of Comparative \& Physiological Psychology, 67, 493-496.

Cranney, J., \& Cohen, M. E. (1985). The glabella startle reflex: Inhibition by frequency and intensity modulations. Perception \& Psychophysics, 37, 28-34.

Crofton, K. M., Sheets, L. P., Dean, K. F., \& Peele, D. B. (1988). The effects of experience on gap inhibition of the acoustic startle. Society of Neuroscience Abstracts, 14, 60.

Davis, M. (1980). Neurochemical modulation of sensory-motor reactivity: Acoustic and tactile startle reflexes. Neuroscience \& Biobehavioral Reviews, 4, 241-263.

DAvIS, M. (1988). The potentiated startle response as a measure of conditioned fear and its relevance to the neurobiology of anxiety. In P. Simon \& P. Soubrie (Eds.), Animal models of psychiatric disorders (pp. 61-89). Basel: S. Karger.

Davis, M., Gendelman, D. S., Tischler, M. D., \& Gendelman, P. M. (1982). A primary acoustic startle circuit: Lesion and stimulation studies. Journal of Neuroscience, 2, 791-805.

Dean, K. F., Sheets, L. P., Crofton, K. M., \& Retter, L. W. (1990). The effect of age and experience on inhibition of the acoustic startle response by gaps in background noise. Psychobiology, 18, 89-95.

FitzgibBons, P. J., \& Wightman, F. L. (1982). Gap detection in normal and hearing impaired listeners. Journal of the Acoustical Society of America, 72, 761-765.

GrenN, D. M. (1971). Temporal auditory acuity. Psychological Review, $78,540-551$.

Hoffman, H. S., \& Ison, J. R. (1980). Reflex modification in the domain of startle: 1 . Some empirical findings and their implication for how the nervous system processes sensory input. Psychological Review, 87, 175-189.

Hoffman, H. S., SEARle, J. L. (1965). Acoustic variables in the modification of startle reaction in the rat. Journal of Comparative \& Physiological Psychology, 60, 53-58.

Hoffman, H. S., \& Searle, J. L. (1968). Acoustic and temporal factors in the evocation of startle. Journal of the Acoustical Society of America, 43, 269-282.

HoffMAN, H. S., \& WiBLE, B. L. (1969). Temporal parameters in startle facilitation by steady background signals. Journal of the Acoustical Society of America, 45, 7-12.

HoFFMAN, H. S., \& WIBLE, B. L. (1970). Role of weak signals in acoustic startle. Journal of the Acoustical Society of America, 47, 489-497.

Ison, J. R. (1982). Temporal acuity in auditory function: Reflex inhibition by brief gaps in noise. Journal of Comparative \& Physiological Psychology, 96, 945-954.

IsoN, J. R. (1984). Reflex modification as an objective test for sensory processing following toxicant exposure. Neurobehavioral Toxicology \& Teratology, 6, 437-445.

Ison, J. R., \& HAMmond, G. R. (1971). Modification of the startle reflex in the rat by changes in the auditory and visual environments. Journal of Comparative \& Physiological Psychology, 75, 435-452.

Ison, J. R., HAMmond, G. R., \& KraUter, E. E. (1973). Effects of experience on stimulus-produced reflex inhibition in the rat. Journal of Comparative \& Physiological Psychology, 83, 324-336.

IsON, J. R., \& LEONARD, D. W. (1971). Effects of auditory stimuli on the amplitude of the nictitating membrane in the rabbit. Journal of Comparative \& Physiological Psychology, 75, 157-164.

Ison, J. R., \& PinckNey, L. A. (1983). Reflex inhibition in humans: Sensitivity to brief silent periods in white noise. Perception \& Psychophysics, 34, 84-88.

Kellogg, C., Ison, J. R., \& Miller, R. K. (1983). Prenatal diazepam exposure: Effects on auditory temporal resolution in rats. Psychopharmacology, 79, 332-337.

KONORSKI, J. (1967). Integrative activity of the brain. Chicago: University of Chicago Press.

Krauter, E. E., Leonard, D. W., \& Ison, J. R. (1973). Inhibition of the human eyeblink by a brief acoustic stimulus. Journal of Comparative \& Physiological Psychology, 84, 246-251.

Pinckney, L. A. (1976). Inhibition of the startle reflex in the rat by prior tactile stimulation. Animal Learning \& Behavior, 4, 467-472.

PLOMP, R. (1964). Rate of decay of auditory sensation. Journal of the Acoustical Society of America, 36, 277-282.

Prokasy, W. F. (1965). Classical conditioning: A symposium. New York: Appleton-Century-Crofts

RAzRAN, G. (1971). Mind in evolution: An East-West synthesis of learned behavior and cognition. Boston: Houghton Mifflin.

Rescorla, R, A. (1967). Pavlovian conditioning and its proper control procedures. Psychological Review, 74, 71-80.

Ruppert, P. H., Dean, K. F., \& Reiter, L. W. (1984). Trimethyltin disrupts acoustic startle responding in adult rats. Toxicology Letters, 22, 33-38.

Russo, J. M., ReITer, L. A., \& Ison, J. R. (1975). Repetitive exposure does not attenuate the sensory impact of the habituated stimulus. Journal of Comparative \& Physiological Psychology, 88, 665-669.

Schwartz, G. M., Hoffman, H. S., Stitt, C. L., \& Marsh, R. R. (1976). Modification of the rat's acoustic startle response by antecedent visual stimulation. Journal of Experimental Psychology: Animal Behavior Processes, 2, 28-37.

StitT, C. L., Hoffman, H. S., \& Marsh, R. R. (1973). Modification of the rat's startle reaction by termination of antecedent acoustic signals. Journal of Comparative \& Physiological Psychology, 84, 207-215.

StitT, C. L., Hoffman, H. S., Marsh, R. R., \& Boskoff, K. J. (1974) Modification of the rat's startle reaction by antecedent change in the acoustic environment. Journal of Comparative \& Physiological Psychology, 86, 826-836.

WECKER, J. R. (1985). Organismic and stimulus factors in the expression of reflex inhibition by sensory prestimulation in the rat. (Doctoral dissertation, University of Rochester.) Dissertation Abstracts International, 46, 1366B.

WECKER, J. R., \& IsON, J. R. (1984). Acute exposure to methyl or ethyl alcohol alters auditory function in the rat. Toxicology \& Applied Pharmacology, 74, 258-266.

Wickens, D. D., \& Wickens, C. D. (1942). Some factors related to pseudoconditioning. Journal of Experimental Psychology, 31, 518-526.

Wu, M.-F., Ison, J. R., Wecker, J. R., \& LAPHAM, L. W. (1985). Cutaneous and auditory function in rats following methyl mercury poisoning. Toxicology \& Applied Pharmacology, 79, 377-388.

WU, M.-F., SuzukI, S. S., \& SiEgel, J. M. (1988). Anatomical distribution and response patterns of reticular neurons active in relation to acoustic startle. Brain Research, 457, 399-406.

(Manuscript received February 28, 1990; revision accepted for publication May 2, 1990.) 